\title{
Compressive properties of chemical vapor deposited zinc sulfide at high temperatures
}

\author{
Tianbao CHENG ${ }^{1,2,3}$, Yong TAO ${ }^{1,2,3, \dagger}$, Weiguo $\mathrm{LI}^{1,2,3}$, Liming CHEN ${ }^{1,2,3}$, Daining FANG ${ }^{4}$ and Yazheng YANG \\ ${ }^{1}$ College of Aerospace Engineering, Chongqing University, Chongqing 400030, China \\ ${ }^{2}$ Chongqing Key Laboratory of Heterogeneous Material Mechanics, Chongqing University, Chongqing 400030, China \\ ${ }^{3}$ State Key Laboratory of Coal Mine Disaster Dynamics and Control, Chongqing University, Chongqing 400030, China \\ ${ }^{4}$ Institute of Advanced Structure Technology, Beijing Institute of Technology, Beijing 100081, China
}

The compressive properties of chemical vapor deposited zinc sulfide are studied up to $1050^{\circ} \mathrm{C}$ for the first time. The specimen with columns parallel to the compression direction fails by shear firstly and then the part below the slip plane is split. The fracture mode changes from intergranular to transgranular as temperature increases. During compression, the load firstly increases rapidly, then decreases gradually, and lastly drops sharply as displacement increases. The compressive strength decreases as temperature increases. Above $8_{00}^{\circ} \mathrm{C}$, recrystallization is driven by diffusional processes, which leads to the reduction in compressive strength because of the grown grains and the increase in strain softening as holding time increases. At higher temperatures, diffusional processes are joined by plastic deformation which leads to strain hardening and results in the increase in compressive strength with holding time. This plastic deformation mechanism during recrystallization is observed directly from the load-displacement curve by the high-temperature in-situ compression test for the first time. (c)2019 The Ceramic Society of Japan. All rights reserved.

Key-words: Zinc sulfide, Chemical vapor deposition, Compressive properties, High temperature, Recrystallization

[Received March 29, 2019; Accepted May 14, 2019]

\section{Introduction}

Zinc sulfide $(\mathrm{ZnS})$ has a wide bandgap $\left[E_{\mathrm{g}}=3.68 \mathrm{eV}\right.$ at room temperature $(\mathrm{RT})]^{1)}$ and low-energy fundamental phonon modes. ${ }^{2)}$ The former property allows $\mathrm{ZnS}$ to transmit visible light and the latter long-wave infrared (IR) wavelengths $(8-12 \mu \mathrm{m})$. $\mathrm{ZnS}$ has thus been the only other material besides diamond that can transmit from visible light to long wave IR wavelengths even to microwave rang. ${ }^{3)}$ Besides, cubic $\mathrm{ZnS}$ is also optically isotropic. ${ }^{4)}$ The unique combination of these properties makes $\mathrm{ZnS}$ potential candidate for a range of optical engineering applications, such as, the IR windows, optical thin films, photonic crystals, phosphors, and electroluminescent devices. ${ }^{2), 5)-8)}$

Optical grade $\mathrm{ZnS}$ is commonly synthesized by chemical vapor deposition (CVD) because of the obvious advantages over other techniques, especially in the ease and accuracy of controlling the stoichiometry and purity of the product. ${ }^{5)-8)}$ However, CVD $\mathrm{ZnS}$ not only has poor transmission in the visible and $3-5 \mu \mathrm{m}$ regions, but also has absorption band at $6.5 \mu \mathrm{m}^{2,5)-8)}$ To improve the transmission properties, post thermal treatments are usually required. How the microstructure of $\mathrm{CVD} \mathrm{ZnS}$ changes

Corresponding author: Y. Tao; E-mail: taoyong@pku.edu. cn during this process and the resulting improvement in transmission properties have been studied. ${ }^{2), 5)-11)}$ However, the compressive properties at high temperatures in-situ are still not known although it is important for the post thermal treatments.

In addition, the thermal properties of $\mathrm{CVD} \mathrm{ZnS}$ were reported up to temperatures approach or exceed $\left.1000^{\circ} \mathrm{C},{ }^{9}\right)$ but the mechanical properties reported were mainly limited to $600^{\circ} \mathrm{C}$. ${ }^{9), 12)-20)}$ However, as a potential candidate for the IR side window and radome of high-speed vehicles, CVD ZnS can be subjected to severe aerodynamic heating and services at temperatures $>600^{\circ} \mathrm{C}$ especially in some local regions because of the inhomogeneous temperature distribution in the IR side window and radome. ${ }^{21)-24)}$ As is known, the maximum compressive stress is usually a few times higher than the maximum tensile stress under aerodynamic thermal environments. ${ }^{21)-23)}$ However, it is different from the other bulk ceramics that the compressive strength of $\mathrm{ZnS}$ is relatively low. ${ }^{18)-20)}$ Thus, the compressive properties become critical in the design and evaluation of $\mathrm{ZnS}$ IR side window and radome.

In the present work, the compressive properties of CVD ZnS are studied up to $1050^{\circ} \mathrm{C}$ for the first time. Recrystallization effects are included. The failure mechanisms being responsible for the mechanical behaviors are analyzed. The results contribute to a broader understand- 
ing of the mechanical properties of CVD $\mathrm{ZnS}$ at elevated temperatures. At the same time, the study is not only useful for the post thermal treatments of CVD $\mathrm{ZnS}$, but also for the design, application, and evaluation of the CVD $\mathrm{ZnS}$ in the IR optical engineering.

\section{Experimental procedure}

The CVD ZnS specimens used in this study were obtained from Beijing Guojing Infrared Optical Technology, Co., Ltd., Beijing, China, in finished form. The relative density is $99.5 \%$. The detailed preparation processes were published previous. ${ }^{3), 11)}$ The final specimen dimensions were $5 \times 5 \times 12.5 \mathrm{~mm}$ (length $\times$ width $\times$ height $)$ in accordance with Awaji and Nagano. ${ }^{25)}$ The growth direction is parallel to the height direction. It is worth noting that there is an orientation selection which leads to the $\langle 100\rangle$ crystallographic direction of $\mathrm{ZnS}$ perpendicular to the substrate during CVD process. Along this direction, the grains grow more rapidly, leading to the development of columnar structure. For the microstructures of the samples before mechanical tests, see Fu et al. ${ }^{3)}$

The compressive properties of CVD $\mathrm{ZnS}$ were measured on the ultra-high temperature testing machine developed by the authors. ${ }^{26)}$ The pressure in the hightemperature furnace was vacuumed to $<5 \mathrm{~Pa}$, followed by introducing high purity argon $(>99.999 \%$ ), up to the standard atmospheric pressure. The heating rate is $\sim 50{ }^{\circ} \mathrm{C} \mathrm{min}^{-1}$. To reach a thermal equilibrium, the specimen was held at each testing temperature for $10 \mathrm{~min}$. Particularly, to study the recrystallization effects, longer holding time (i.e., 30, 60, or $90 \mathrm{~min}$ ) was used. The temperature fluctuation at each holding temperature was $< \pm 3^{\circ} \mathrm{C}$. The beam speed of the test machine was 0.5 $\mathrm{mm} \mathrm{min}^{-1}$. In each case, $3-5$ specimens were tested based on the dispersion of the results. The microstructures after testing were observed by scanning electron microscopy (SEM; S-4800, Hitachi, Ltd., Tokyo, Japan).

\section{Results and discussion}

The compressive properties of CVD ZnS from RT to $1050^{\circ} \mathrm{C}$ were measured. The typical load-displacement curves are shown in Fig. 1. It can be seen that the load firstly increases rapidly, then decreases gradually, and lastly drops sharply as displacement increases. Nonlinear deformation arises before reaching the peak point, followed by strain softening. Both nonlinear deformation behavior and strain-softening phenomenon increase significantly as temperature increases [Fig. 1(a)]. It can be seen that significant strain softening arises above $800^{\circ} \mathrm{C}$. CVD ZnS shows a little nonlinearity at $900^{\circ} \mathrm{C}$ when holding time $t=10 \mathrm{~min}$, but significant nonlinear deformation (i.e., strain hardening) as holding time increases [Fig. 1(b)]. These demonstrate that it is different from the traditional bulk ceramics that linear elastic theory doesn't apply and nonlinear constitutive relation should be adopted when designing and evaluating the CVD ZnS components in the IR optical engineering, especially at hightemperature conditions.
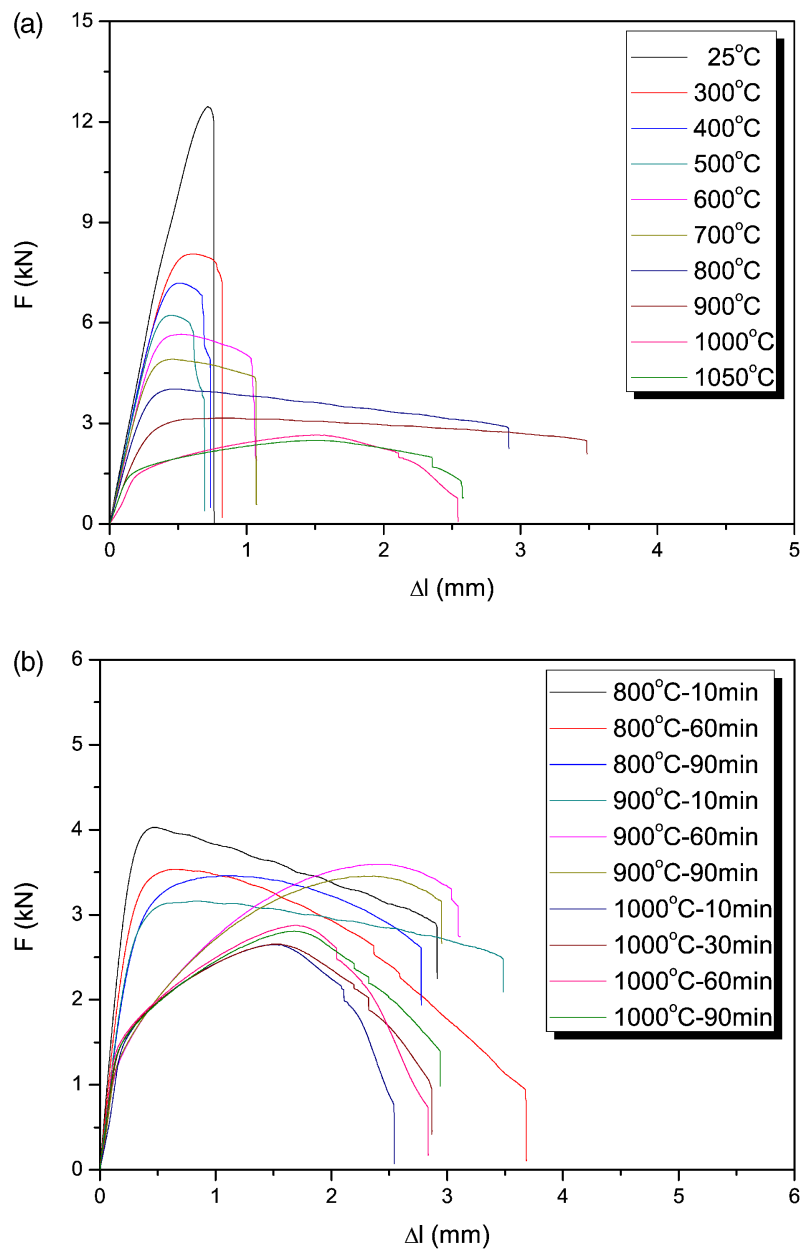

Fig. 1. The typical load-displacement curves of CVD $\mathrm{ZnS}$, in (a) $T=\mathrm{RT}-1050^{\circ} \mathrm{C}$ and $t=10 \mathrm{~min}$, and in (b) $T=800-1000^{\circ} \mathrm{C}$ and $t=10-90 \mathrm{~min}$.

The compressive strength of CVD $\mathrm{ZnS}$ from $\mathrm{RT}$ to $1050^{\circ} \mathrm{C}$ is shown in Fig. 2. One can see that the compressive strength decreases as temperature increases [Fig. 2(a)]. Holding time almost has no effect on the compressive strength below $800^{\circ} \mathrm{C}$. Above this temperature, as well known, recrystallization occurs. ${ }^{2)}$ This leads to the reduction in compressive strength with increasing holding time because of the grown grains [see case of $T=800^{\circ} \mathrm{C}$ in Fig. 2(b)]. As temperature increases further, the compressive strength can increase with increasing holding time [see the cases at 900 and $1000^{\circ} \mathrm{C}$ when holding time changes from 10 to $60 \mathrm{~min}$ in Fig. 2(b)]. This should be attributed to the fact that diffusional processes are joined by plastic deformation at higher temperatures, leading to strain hardening, as shown in Fig. 1(b), in which a typical example is the variation of load-displacement curve at $900^{\circ} \mathrm{C}$ when holding time changes from 10 to $60 \mathrm{~min}$. This recrystallization mechanism was suggested by Karaksina et al. ${ }^{27), 28)}$ from the microstructure and porosity changes after post thermal treatments. Here, this plastic deformation mechanism is observed directly from the loaddisplacement curve by the high-temperature in-situ compression test for the first time. 

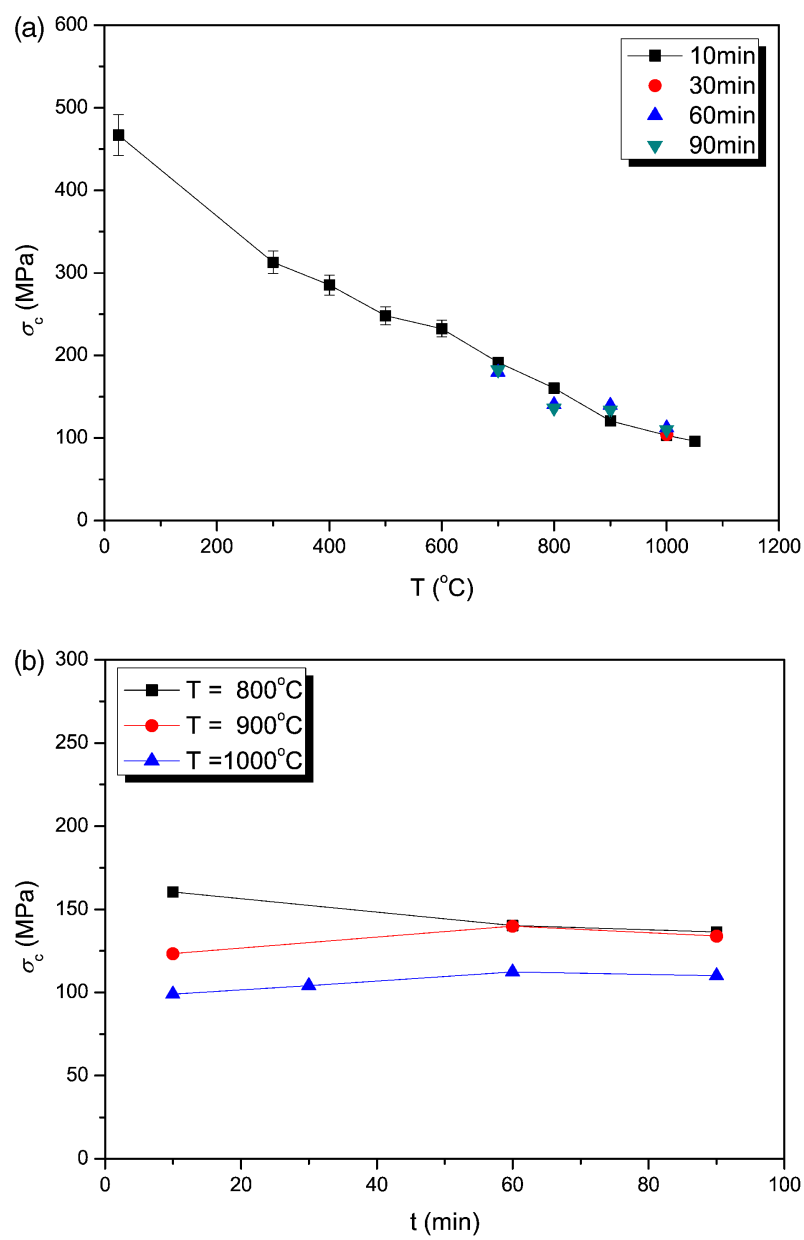

Fig. 2. The compressive strength of CVD ZnS (a) versus testing temperature for various holding time and (b) versus holding time for different testing temperatures. Note that the error bars for some points are too small to see.

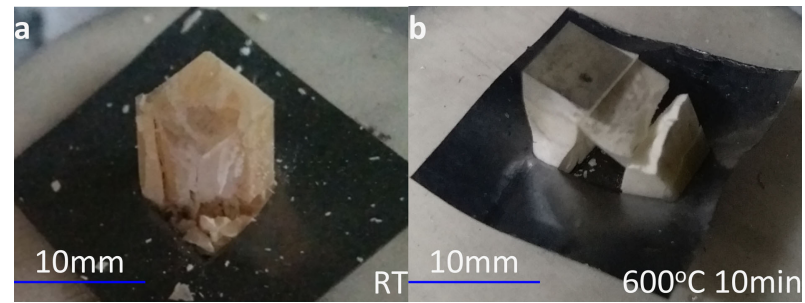

Fig. 3. The typical samples after testing.

To further analyze the fracture behavior and reveal the failure mechanisms of CVD $\mathrm{ZnS}$ at elevated temperatures, the typical samples and SEM photos of the main fragments after testing are shown in Figs. 3 and 4, respectively. During compression, the specimen fails by shear firstly and then the part below the slip plane is split. The specimen is crushed into many small columns between RT and $300^{\circ} \mathrm{C}$ and is of high-energy fracture [Fig. 3(a)]. However, above $300^{\circ} \mathrm{C}$, the column number decreases significantly and a few main parts are resulted [Fig. 3(b)]. From Fig. 4(a), one can see that the fractured surface shows uneven facets evenly in all direction between RT and $300^{\circ} \mathrm{C}$. However, above $300^{\circ} \mathrm{C}$, grain orientation can be

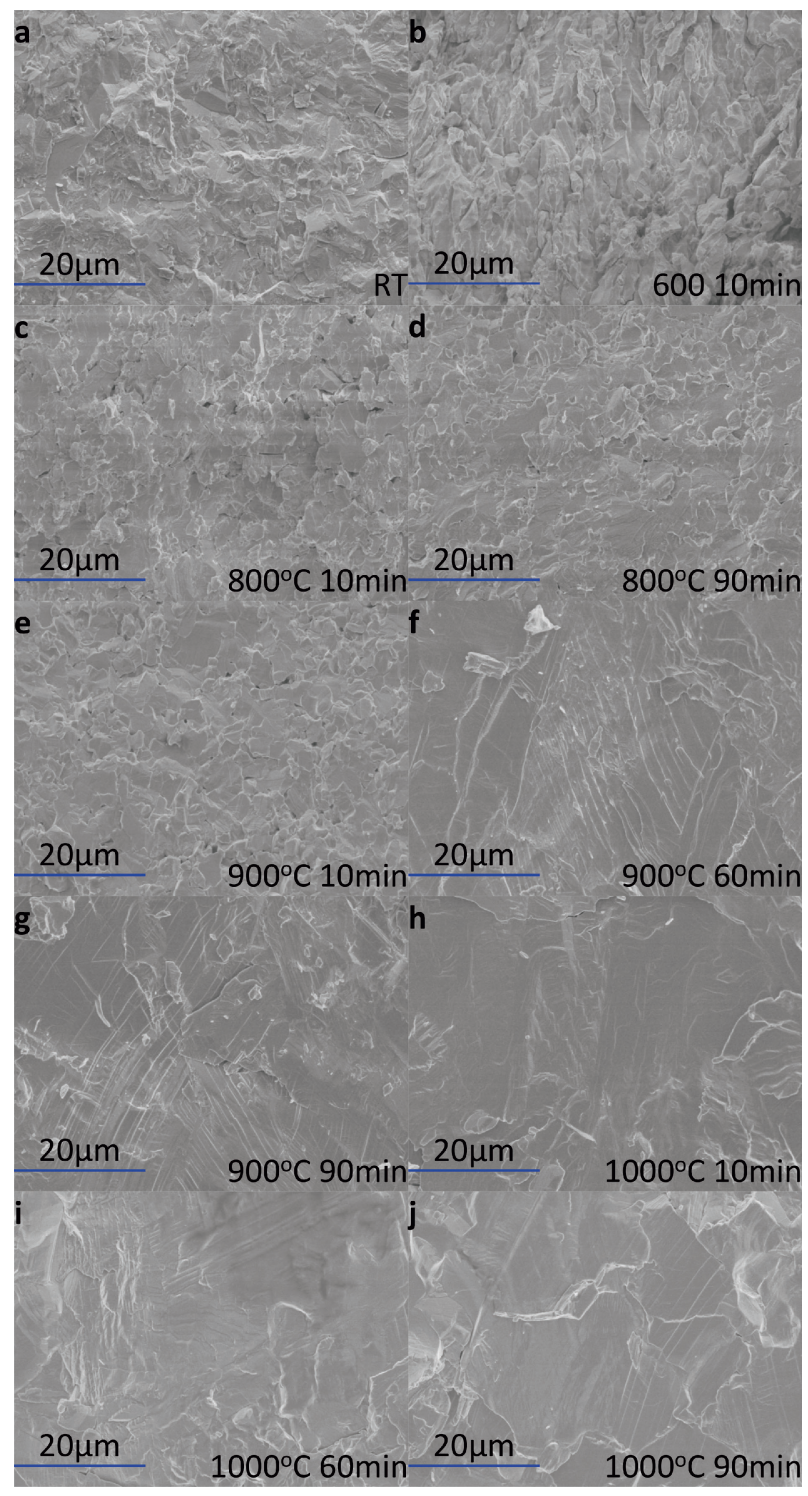

Fig. 4. The typical SEM fractographs of the main fragments after testing for different testing temperatures and holding time.

clearly observed on the fractured surface [Fig. 4(b)]. This suggests that CVD ZnS mainly fractures at the interfaces of the columns as temperature increases.

From Figs. 4(a) and 4(c), one can see that the grains grow up at $800^{\circ} \mathrm{C}$. At the same time, some voids present. This demonstrates that recrystallization occurs. Similar phenomenon can also be observed at $800^{\circ} \mathrm{C}$ with $t=90$ min and $900^{\circ} \mathrm{C}$ with $t=10 \mathrm{~min}$ [Figs. 4(d) and 4(e)]. With increased temperature or holding time, the grains further grow up significantly and voids disappear [Figs. 4(f)$4(j)]$. It can be seen that grain recombination leads to the formulation of large grain, reduces the grain boundaries thus the resistance for crack propagation, increases the extent of transgranular fracture, and finally results in the strength reduction. Besides, lots of slip evidence can be observed clearly in Figs. 4(f)-4(j). This is consistent with the observed plastic deformation at $900^{\circ} \mathrm{C}$ with $t=60$ and $90 \mathrm{~min}$ and at $1000^{\circ} \mathrm{C}$. 
Finally, one can see that apparent geometrical structure change can be observed at $1000^{\circ} \mathrm{C}$ with $t=60$ and $90 \mathrm{~min}$ [Figs. 4(i) and 4(j)] because of significant sublimation. This is why the tests are limited to $1050^{\circ} \mathrm{C}$ in this work.

\section{Conclusions}

The compressive properties of CVD ZnS with columns parallel to the compression direction were investigated from RT to $1050^{\circ} \mathrm{C}$ for the first time. The load firstly increases rapidly, then decreases gradually, and lastly drops sharply as displacement increases. Nonlinear deformation occurs before reaching the peak point. After that strain softening arises. Both nonlinear deformation behavior and strain-softening phenomenon increase significantly as temperature or holding time increases because of recrystallization. The compressive strength decreases as temperature increases. Above $800^{\circ} \mathrm{C}$, the compressive strength decreases as holding time increases because that grains grow up during recrystallization. As temperature increases further, the compressive strength can increase with holding time as diffusional processes are joined by plastic deformation which leads to strain hardening. This plastic deformation mechanism during recrystallization is observed directly from the load-displacement curve by the high-temperature in-situ compression test for the first time.

Acknowledgments This work was supported by the National Natural Science Foundation of China (No. 11802019), the Fundamental Research Funds for the Central Universities (No. 2019CDXYHK0001), the Preferential Funds for the Postdoctors Residing in and Coming to Chongqing to Work (No. 2018LY48), and the Postdoctoral Innovation Talents Support Program of Chongqing.

\section{References}

1) P. Y. Yu and M. Cardona, "Fundamentals of Semiconductors: Physics and Materials Properties", 3rd ed., Springer, Berlin (2005).

2) J. S. McCloy, R. Korenstein and B. Zelinski, J. Am. Ceram. Soc., 92, 1725-1731 (2009).

3) L. G. Fu, C. S. Huo, F. C. Zhang, N. G. Wei, X. W. Wang and F. X. Lv, Infrared Laser Eng., 41, 139-143 (2012).

4) D. C. Harris, Proc. SPIE, 6545, 654502 (2007).

5) P. Ramavath, N. Ravi, U. S. Hareesh, R. Johnson and N. E. Prasad, T. Indian I. Metals, 63, 847-852 (2010).

6) P. Biswas, R. S. Kumar, P. Ramavath, V. Mahendar, G. V. N. Rao, U. S. Hareesh and R. Johnson, J. Alloy. Compd., 496, 273-277 (2010).

7) P. Ramavath, P. Biswas, R. S. Kumar, V. Mahendar,
G. V. N. Rao, U. S. Hareesh, R. Johnson and N. E. Prasad, Ceram. Int., 37, 1039-1046 (2011).

8) P. Ramavath, V. Mahender, U. S. Hareesh, R. Johnson, S. Kumari and N. E. Prasad, Mater. Sci. Eng. A, 528, 5030-5035 (2011).

9) D. C. Harris, M. Baronowski, L. Henneman, L. LaCroix, C. Wilson, S. Kurzius, B. Burns, K. Kitagawa, J. Gembarovic, S. M. Goodrich, C. Staats and J. J. Mecholsky, Jr., Opt. Eng., 47, 114001 (2008).

10) R. Johnson, P. Biswas, P. Ramavath, R. S. Kumar and G. Padmanabham, Trans. Ind. Ceram. Soc., 71, 73-85 (2012).

11) H. Yang, C. S. Huo, H. Z. Yu, L. G. Fu, H. C. Shi, N. O. Lu, W. C. Huang, J. Y. Sun, R. Zheng and X. P. Su, J. Appl. Opt., 29, 57-61 (2008).

12) J. D. Spain and H. S. Starrett, Biaxial Flexural Evaluations of Zinc Sulfide, Southern Research Institute Report SRI-MME-88-259-6270, Birmingham, Alabama (1988).

13) A. A. Déom, D. L. Balageas, F. G. Laturelle, G. D. Gardette and G. J. Freydefont, Proc. SPIE, 1326, 301309 (1990).

14) C. S. J. Pickles and J. E. Field, J. Mater. Sci., 29, 11151120 (1994).

15) Z. L. Qu, X. M. Cheng, R. J. He, Y. M. Pei, R. B. Zhang and D. N. Fang, J. Alloy. Compd., 682, 565-570 (2016).

16) T. B. Cheng, W. G. Li, Z. L. Qu, W. B. Wen and D. N. Fang, Trans. Ind. Ceram. Soc., 75, 215-219 (2016).

17) H. M. Li, T. B. Cheng, Y. B. Ma, B. S. Xu, D. N. Fang and Y. Z. Yang, Int. J. Appl. Mech., 9, 1750070 (2017).

18) T. B. Cheng, W. G. Li, R. B. Zhang and D. N. Fang, Mater. Lett., 158, 140-142 (2015).

19) T. B. Cheng, W. G. Li, R. B. Zhang and D. N. Fang, High Temp. High Press., 46, 133-140 (2017).

20) T. B. Cheng, Y. B. Ma, H. M. Li, D. N. Fang and Y. Z. Yang, J. Alloy. Compd., 729, 1086-1092 (2017).

21) Y. C. Liu, Y. R. He, J. Q. Zhu, J. C. Han and D. L. Quan, J. Zhejiang Univ.-Sci. A, 15, 185-196 (2014).

22) Y. C. Liu, Y. R. He, F. L. Tian and J. Q. Zhu, Chin. J. Aeronauti., 27, 266-271 (2014).

23) Y. C. Liu, Y. R. He, Z. G. Yuan, J. Q. Zhu and J. C. Han, J. Alloy. Compd., 589, 101-108 (2014).

24) M. S. Cheng and L. Z. Chen, Aerosp. Mater. Technol., 40, 73-75 (2010).

25) H. Awaji and Y. Nagano, J. Ceram. Soc. Jpn., 101, 945950 (1993).

26) T. B. Cheng, W. G. Li, Q. M. Li, H. B. Kou and D. N. Fang, High Temp. High Press., 43, 285-295 (2014).

27) E. V. Yashina, E. M. Gavrishchuk and V. B. Ikonnikov, Inorg. Mater., 40, 1035-1038 (2004).

28) E. V. Karaksina, V. B. Ikonnikov and E. M. Gavrishchuk, Inorg. Mater., 43, 452-454 (2007). 